\title{
Editorial Note: Sparse Representation and Image Processing
}

(C) Springer Science+Business Media, LLC, part of Springer Nature 2019

Multimedia Tools and Applications gratefully acknowledges the editorial work of the scholars listed below on the special issue entitled, "Sparse Representation and Image Processing."

Of 68 papers submitted to this issue, 22 were eventually accepted after a stringent peerreview process.

\author{
Kaijian Xia (Lead Guest Editor) \\ China University of Mining Technology \\ 1 \\ Department of Information, Changshu No.1 People's Hospital \\ Changshu, Jiangsu \\ China \\ lb17060008@cumt.edu.com
}

\section{Sheng-rong Gong}

Soochow University

China

shrgong@suda.edu.cn

\section{Behnaz Ghoraani}

Florida Atlantic University

Institute for Sensing and Embedded Network Systems Engineering

USA

bghoraani@fau.edu

Publisher's note Springer Nature remains neutral with regard to jurisdictional claims in published maps and institutional affiliations. 